\section{Molecular Identification of Commercial Apple Cultivars with Microsatellite Markers}

\author{
Zsolt Galli ${ }^{1}$ \\ HAS-St. István University Research Group for Molecular Plant Breeding, \\ H-2103 Gödöllö, Hungary
}

Gábor Halász, Erzsébet Kiss, and László Heszky

St. István University, Department of Genetics and Plant Breeding, H-2103 Gödöllö, Hungary

Judit Dobránszki

Research Centre of University of Debrecen, H-4400, Nyiregyháza, Hungary

Additional index words. Malus $\times$ domestica, genotyping, somaclonal mutations

\begin{abstract}
A collection of 66 commercial apple (Malus $\times$ domestica Borkh.) cultivars was screened with six previously described SSR (Simple Sequence Repeat) markers for molecular identification. In total, 55 polymorphic alleles were detected at the 6 SSR loci (average 9.2 alleles per locus) and the polymorphism information content (PIC) averaged 0.72 . Successful differentiation of all apple genotypes except for somatic mutants was accomplished by using only four (CH03g07, CH04e03, CH05d11, and CH05e03) SSR markers. Sport mutants proved to be indistinguishable from each other and their progenitors. The cumulative probability of obtaining an identical SSR profile for two randomly chosen apple genotypes was $1.79 \times 10^{-4}$, which confirms the high potential of simple sequence repeats (SSRs) for cultivar identification.
\end{abstract}

The accessibility of reliable genetic markers is essential for variety identification and distinction, for development of efficient breeding methods to create new apple cultivars selected for disease resistance, fruit quality or tree growth characteristics and other traits. The emergence of PCR-based molecular markers has created the opportunity for finescale genetic characterizations of germplasm collections, as well. Microsatellites (SSRs) are the most widely used molecular markers in this field. Repetitive nucleotide sequences are ubiquitously found in eukaryotic nuclear genomes and their flanking regions are highly conserved, which make them suitable for amplifying the usually polymorphic intervening repeat loci. Microsatellites show high polymorphism, co-dominant inheritance and good reproducibility. Since all individuals of the same cultivar originated from a single progenitor by vegetative propagation in apple breeding and cultivation, SSR fingerprinting can be used for cultivar differentiation. Up to now, almost 200 SSR markers are available in apple (Guilford et al., 1997; Gianfranceschi et al., 1998; Hokanson et al., 1998; Liebhard et al., 2002). SSR markers have proven to be highly informative and useful for distinguishing genotypes and for determining genetic relationships among Malus cultivars and species (Goulão and Oliveira, 2001; Hokanson et al., 2001;

Received for publication 22 July 2005 . Accepted for publication 2 Sept. 2005. Thanks to Eszter Agócs and Tímea Kutyik for technical assistance. Financial support was provided by the Hungarian Scientific Research Fund (OTKA F63582 and TO37251).

${ }^{1}$ Corresponding author; e-mail galli.zsolt@mkk. szie.hu.
Laurens et al., 2004; Liebhard et al., 2002). In this study six previously described SSR markers (Liebhard et al., 2002) were applied to distinguish 66 different apple cultivars.

\section{Materials and Methods}

Young apple leaves used for DNA purification were collected at the Research and Extension Centre for Fruit Growing, Újfehértó, Hungary. Genomic DNA was extracted using a DNeasy Plant Mini Kit (Qiagen) and PCR amplifications were carried out by a Perkin Elmer 9700 thermocycler using Cy-5 labelled SSR primers. The six applied pairs of oligonucleotide primers (CH03g07, $\mathrm{CH} 04 \mathrm{e} 03$, $\mathrm{CH} 04 \mathrm{~g} 10, \mathrm{CH} 05 \mathrm{c} 02, \mathrm{CH} 05 \mathrm{~d} 11$, and $\mathrm{CH} 05 \mathrm{e} 03$ ) have already been identified and published (Liebhard et al., 2002). The reactions were performed in a final volume of $20 \mu \mathrm{L}$, the reaction mixture consisted of the following components: $50 \mathrm{ng}$ template DNA, $1 \times$ PCR buffer (50 mM KCl, 10 mM Tris-HCl pH: 8.3, $1.1 \mathrm{mM} \mathrm{MgCl}, 0.01 \%$ gelatin), plus $0.9 \mathrm{mM}$ $\mathrm{MgCl}_{2}, 0.3 \mu \mathrm{M}$ of both primers, $0.2 \mathrm{~mm}$ each of dNTPs and 1.2 U of Red-Taq DNA polymerase (Sigma). The cycling profile consisted of an initial denaturation step of 2 min followed by 35 cycles of $20 \mathrm{~s}$ at $94^{\circ} \mathrm{C}, 30 \mathrm{~s}$ at $56^{\circ} \mathrm{C}$ and $60 \mathrm{~s}$ at $72{ }^{\circ} \mathrm{C}$. The amplification process was finished with $5 \mathrm{~min}$ at $72{ }^{\circ} \mathrm{C}$. Products were preliminarily tested by running on $1.2 \%$ agarose gel, necessarily diluted with TE1 buffer (10 mM Tris, $1 \mathrm{~mm}$ EDTA) up to 30 times and microsatellite alleles were visualized and determined in ALFexpress-II DNA analyzer (Amersham BioSciences), following standard protocols. ALF express sizer 50-500 was ap- plied as internal standard. PCR amplifications using the same extracted DNA as template and allele size determination were repeated at least twice.

Based on the frequencies of observed microsatellite alleles, polymorphic information content (PIC) was calculated by the formula: $\mathrm{PIC}=1-\sum p_{i}^{2}$, where $p_{i}$ is the frequency of the ith allele of each SSR marker (Anderson et al. 1993). It is essentially the same as the index of heterozygosity. To find the optimal combination and minimum set of markers for identification, the undistinguishable sport mutations were treated as single cultivars so data of 46 different cultivars $(\mathrm{N}=46)$ were analyzed according to Tessier et al. (1999). At first, the confusion probability (C) was calculated, i.e. the probability that two randomly chosen individuals from the sample of 46 cultivars have identical banding patterns. The confusion probability is for the $i$ th pattern of the given $j$ th primer present at frequency $p_{i}$ in this set of cultivars is:

$$
c_{i}=p_{i} \frac{(N p,-1)}{N-1}
$$

For the $j$ th primer, the confusion probability $C_{j}$ is equal to the sum of the different $c_{i}$ for all $I$ patterns generated by the primer:

\section{$+\sum e_{6}$}

The probability of identity (PI) of obtaining same SSR profile for two randomly chosen apple cultivars was calculated by the formula

$P I=\prod c$,

The total number of nondifferentiated pairs of cultivars for the $j$ th primer is given by

$$
x y=\frac{N(N-1)}{2} C \text {. }
$$

For a given combination of $k$ primers, this number is as follows (Tessier et al., 1999).

$$
x_{4}=\frac{N(N-1)}{2} \prod_{j} c_{j}
$$

\section{Results and Discussion}

Each applied SSR primer-pair generated reliable microsatellite alleles in all 66 apple cultivars. A total of 55 polymorphic alleles were amplified and the number of alleles per marker ranged from 6-13, with an average of 9.2 (Table 1). These markers were chosen by allelic diversity, the rarely visible stuttered bands near the specific product caused by the slippage of Taq polymerase, and considering their reliability, which was verified by repeated tests. The allele sizes determined by the same markers were identical in all replications. Table 2 shows the allelic composition and frequency of each SSR marker based on the results of all 66 cultivars.

Some new allelic forms were detected when comparing our results with those already published by Liebhard et al. (Table 1). This could be explained by the small number of cultivars (seven cultivars and one breeding selection) tested in the above mentioned study. Obviously, this is the reason for the difference of PIC values, as well. Since four cultivars ('Fiesta', 'Florina', 'Prima', and 'Starking') 
were common in both studies, the reproducibility of SSR markers could be tested. In general, it was adequate, except for the marker $\mathrm{CH} 05 \mathrm{e} 03$, for which three base-pair differences were observed probably due to the different size markers used. It supports the perception that the relative size of the alleles is the most important because many factors can modify the migration of fragments through the gel during size determination. Liebhard et al. (2002) used a 10-bp DNA ladder which gave them strikingly consistent, highly accurate results since with the other five SSR markers their allele sizes were the same as ours. It should be noted that alleles of $\mathrm{CH} 05 \mathrm{e} 03$ marker in 'Starking' were 186:188 according to Liebhard et al. (2002) while we found the same alleles homozygous 191:191 instead of the expected 189:191, considering the shift of three base pairs for this marker. Since in all somatic mutants of 'Starking' the $\mathrm{CH} 05 \mathrm{e} 03$ marker amplified only one 191-bp band in our study (Table 3) we presume that this allele is homozygous and the 186-bp band in the other study could be caused by the slippage of the polymerase enzyme (stutter bands). Another difference was found in 'Prima' where an additional new allele (165 bp) was detected using marker CH03g07.

As can be seen in Table 2 almost every SSR marker had one or two characteristic allele(s) with high occurrence. These alleles can possibly be considered as setpoints of sequence repeats and new alleles might derive from the increase or decrease of the number of repeats. The 135-bp allele at the locus $\mathrm{CH} 04 \mathrm{~g} 10$ had the highest frequency, and occurred in $60 \%$ of the genotypes. That is why the PIC of marker $\mathrm{CH} 04 \mathrm{~g} 10$ was the lowest and dropped dramatically when more cultivars were tested (Table 1). Generally, higher number of alleles produces higher PIC values, as well. However, this statement is not always true; the even distribution of allele frequencies is also crucial. For instance, many rare alleles could be determined using the $\mathrm{CH} 05 \mathrm{~d} 11$ marker causing higher number of alleles but lower PIC than in case of markers $\mathrm{CH} 03 \mathrm{~g} 07$ or $\mathrm{CH} 05 \mathrm{c} 02$. The average frequency of alleles proved to be $11 \%$.

Table 3 shows the allele size results at 6 microsatellite loci obtained for 66 apple cultivars. In cases where only one band was visible, its size is reported twice since the genotype is presumed to be homozygous. To determine whether this is a real homozygous allele or a null allele is involved, access to a segregating population is needed. In practice, the intensity of the specific band usually helps. The peak of the real homozygous allele is much higher. The average amount of heterozygotes is $70 \%$ ranging from $41 \%$ to $83 \%$. These values are similar to the already published results of Gianfranceschi et al. (1998), Hokanson et al. (1998), and Liebhard et al. (2002) and slightly lower than those obtained by Laurens et al. (2004). The CH04g10 marker resulted in the most homozygote alleles (59\%) and has the lowest discriminating power.

In case of five cultivars, three distinguishable alleles were determined with at least one primer pair, indicating triploidy; although only three of them ('Charden', 'Jonagold', and 'Sir Prize') are truly triploids. In cultivars 'Akane' and 'Pinova', the additional bands may indicate the presence of another locus. Presumably these are not amplification artifacts since the obtained patterns were the same in all replications. The possible amplification of more than one locus was also observed by Guilford et al. (1997) and Liebhard etal. (2002). Surprisingly, the popular triploid cultivar 'Mutsu' produced only one or two alleles with all six primer pairs, indicates the abundance of homozygous and/or null alleles. Or else, it was just a coincidence, since in other study (Kitahara et al. 2005), among 10 applied SSR markers, 6 produced 3 different alleles in 'Mutsu'.

The accuracy of the obtained SSR data was confirmed by checking the presumed or known parentage of the genotypes in one hybrid ('Jonagold' = 'Golden Delicious' $\times$ 'Jonathan') for which both parents were also analyzed. For many of the other cultivars tested, however, only one of the parents was present among the tested cultivars. Checking these combinations, all data seemed to be consistent, i.e., one of the alleles always originated from the proper parent. For example, the cultivar 'Golden Delicious' was used as one of the parents for developing new hybrid combinations in case of 13 subsequent cultivars ('Angold', 'Charden', 'Elstar', 'Gala', Greensleeves', 'Jonagold', 'Mutsu', 'Ozark Gold', 'Pink Lady', 'Pinova', 'Sampion', 'Sir Prize', and 'Snygold'). In their allelic composition, the presence of one allele from 'Golden Delicious' is always evident. The same situation could be observed with five cultivars ('Akane', 'Florina', 'Idared', 'Jonager', and 'Jonagold') in which 'Jonathan' was used as one of the partners to generate new hybrids with improved features.

Table 1. Microsatellite primer sequences, number and size range of alleles found by Liebhard et al. (2002) and in the present study, and the polymorphism information content (PIC) values of simple-sequence repeat (SSR) markers based on the results of 8 (Liebhard et al. 2002) and 66 (present study) analyzed genotypes. The confusion probabilities (C) were used to find the optimal combination of SSR markers for identification.

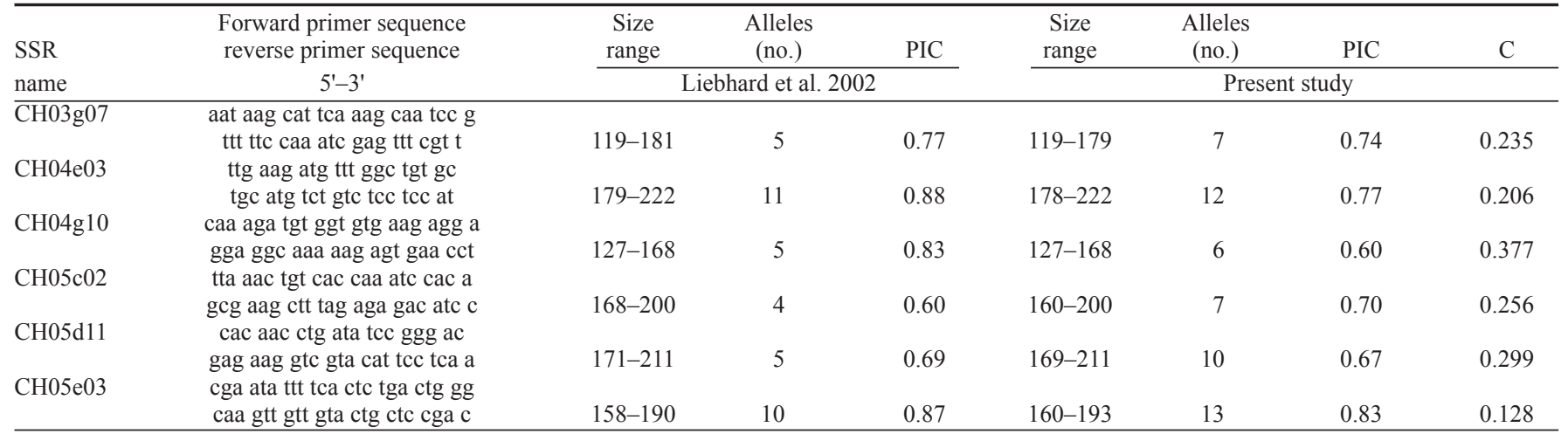

Table 2. Allele sizes in base-pair and frequencies of 6 SSR loci distributed on 66 tested apple cultivars.

\begin{tabular}{|c|c|c|c|c|c|c|c|c|c|c|c|}
\hline \multicolumn{2}{|c|}{$\mathrm{CH} 03 \mathrm{~g} 07$} & \multicolumn{2}{|c|}{$\mathrm{CH} 04 \mathrm{e} 03$} & \multicolumn{2}{|c|}{$\mathrm{CH} 04 \mathrm{~g} 10$} & \multicolumn{2}{|c|}{$\mathrm{CH} 05 \mathrm{c} 02$} & \multicolumn{2}{|c|}{ CH05d11 } & \multicolumn{2}{|c|}{$\mathrm{CH} 05 \mathrm{e} 03$} \\
\hline Size & Frequency & Size & Frequency & Size & Frequency & Size & Frequency & $\overline{\text { Size }}$ & Frequency & Size & Frequency \\
\hline 119 & $25.6 \%$ & 178 & $2.5 \%$ & 127 & $4.4 \%$ & 160 & $5.3 \%$ & 169 & $13.7 \%$ & 160 & $0.8 \%$ \\
\hline 123 & $17.6 \%$ & 184 & $4.2 \%$ & 135 & $60.0 \%$ & 168 & $50.0 \%$ & 171 & $5.1 \%$ & 163 & $16.4 \%$ \\
\hline 127 & $9.6 \%$ & 186 & $10.1 \%$ & 137 & $14.4 \%$ & 170 & $14.0 \%$ & 173 & $53.0 \%$ & 164 & $4.1 \%$ \\
\hline 129 & $38.4 \%$ & 190 & $6.7 \%$ & 139 & $1.1 \%$ & 172 & $3.5 \%$ & 175 & $10.3 \%$ & 168 & $3.3 \%$ \\
\hline 153 & $0.8 \%$ & 196 & $20.2 \%$ & 143 & $8.9 \%$ & 174 & $11.4 \%$ & 181 & $0.9 \%$ & 172 & $3.3 \%$ \\
\hline 165 & $4.0 \%$ & 198 & $41.2 \%$ & 168 & $11.1 \%$ & 176 & $4.4 \%$ & 187 & $2.6 \%$ & 173 & $11.5 \%$ \\
\hline 179 & $4.0 \%$ & 202 & $5.9 \%$ & & & 200 & $11.4 \%$ & 195 & $0.9 \%$ & 175 & $0.8 \%$ \\
\hline & & 204 & $3.4 \%$ & & & & & 197 & $12.0 \%$ & 176 & $0.8 \%$ \\
\hline & & 208 & $2.5 \%$ & & & & & 205 & $0.9 \%$ & 179 & $15.6 \%$ \\
\hline & & 210 & $1.7 \%$ & & & & & 211 & $0.9 \%$ & 181 & $0.8 \%$ \\
\hline & & 216 & $0.8 \%$ & & & & & & & 185 & $29.5 \%$ \\
\hline & & 222 & $0.8 \%$ & & & & & & & 191 & $9.8 \%$ \\
\hline & & & & & & & & & & 193 & $3.3 \%$ \\
\hline
\end{tabular}


As a consequence, microsatellite markers can also be used for identification of ancestries in unknown hybrid combinations and crossings (Cabe etal., 2005; Kitahara et al., 2005). In special cases, the pollen and ovule donor parents can be identified, as well. For instance, besides the triploidy of 'Jonagold' (presence of three different alleles) it was possible to determine which parent provided the ovule (two 198-bp alleles derived from 'Golden Delicious') and which one the pollen grain (one 186-bp allele present from 'Jonathan') with the $\mathrm{CH} 04 \mathrm{e} 03$ SSR marker. The 196-bp allele of 'Jonathan' did not take part in the generated cultivar 'Jonagold'. Surprisingly, for all other markers

Table 3. Allelic composition of 66 apple cultivars analyzed by 6 SSR markers. ${ }^{2}$

\begin{tabular}{|c|c|c|c|c|c|c|}
\hline Cultivar & $\mathrm{CH} 03 \mathrm{~g} 07$ & $\mathrm{CH} 04 \mathrm{e} 03$ & $\mathrm{CH} 04 \mathrm{~g} 10$ & $\mathrm{CH} 05 \mathrm{c} 02$ & $\mathrm{CH} 05 \mathrm{~d} 11$ & $\mathrm{CH} 05 \mathrm{e} 03$ \\
\hline Akane & $123: 179$ & $196: 210: 216$ & $135: 143$ & $170: 200$ & $173: 173$ & $185: 185$ \\
\hline Braeburn & $127: 129$ & 198:202 & $168: 168$ & $168: 168$ & $171: 173$ & 191:191 \\
\hline Charden & 119:129:129 & $198: 198: 198$ & $135: 135: 135$ & 168:174:200 & 169:173:175 & 175:179:185 \\
\hline Red Elstar & 119:119 & 190:198 & $135: 135$ & $168: 170$ & 173:187 & $164: 179$ \\
\hline Fiesta & 119:123 & $186: 196$ & $135: 135$ & $168: 168$ & $173: 197$ & $164: 185$ \\
\hline Florina & $123: 127$ & 196:198 & $135: 168$ & $168: 200$ & 173:197 & 163:191 \\
\hline Gala & 119:129 & 196:198 & $135: 135$ & $168: 170$ & $173: 173$ & 173:185 \\
\hline Galaxy & 119:129 & 196:198 & $135: 135$ & 168:170 & 173:173 & 173:185 \\
\hline Imperial Gala & 119:129 & 196:198 & $135: 135$ & 168:170 & 173:173 & 173:185 \\
\hline Regal Prince (Gala Must) & 119:129 & 196:198 & $135: 135$ & 168:170 & 173:173 & 173:185 \\
\hline Royal Gala & 119:129 & 196:198 & $135: 135$ & $168: 170$ & $173: 173$ & 173:185 \\
\hline Gloster & $123: 129$ & 198:198 & 127:137 & $160: 168$ & 195:197 & 160:191 \\
\hline Golden Delicious & 119:129 & 198:198 & $135: 135$ & 168:174 & 169:173 & 179:185 \\
\hline Granny Smith & $129: 153$ & 196:198 & $127: 137$ & $160: 172$ & $171: 173$ & 168:181 \\
\hline Greensleeves & $129: 129$ & 190:198 & $135: 143$ & $170: 174$ & $171: 173$ & $173: 185$ \\
\hline Idared & 123:129 & 186:198 & $135: 135$ & 168:200 & 173:197 & 172:185 \\
\hline Red Idared & 123:129 & 186:198 & $135: 135$ & $168: 200$ & 173:197 & 172:185 \\
\hline Jerseymac & $165: 165$ & $184: 198$ & $135: 137$ & $160: 176$ & 173:197 & $163: 173$ \\
\hline Jonager & $123: 127$ & 196:196 & $135: 135$ & $170: 200$ & $173: 175$ & $168: 185$ \\
\hline Jonagold & 119:123:129 & $186: 198: 198$ & $135: 135: 135$ & $168: 174: 200$ & 169:173:175 & $163: 179: 185$ \\
\hline Jonathan & 119:123 & 186:196 & $135: 135$ & $168: 200$ & 173:175 & $163: 185$ \\
\hline$\overline{\text { Jonathan M41 }}$ & $119: 123$ & 186:196 & $135: 135$ & $168: 200$ & 173:175 & 163:185 \\
\hline Jonathan Csányi1 & $119: 123$ & 186:196 & $135: 135$ & $168: 200$ & 173:175 & $163: 185$ \\
\hline Red Jonathan & 119:123 & 186:196 & 135:135 & 168:200 & 173:175 & $163: 185$ \\
\hline Szatmárcsekei Jonathan & 119:123 & 186:196 & 135:135 & 168:200 & 173:175 & 163:185 \\
\hline Watson Jonathan & 119:123 & 186:196 & $135: 135$ & 168:200 & $173: 175$ & $163: 185$ \\
\hline Pinova & 119:127:129 & $198: 222$ & $127: 135$ & $168: 174$ & $169: 173$ & 163:179:185 \\
\hline Piros & $165: 179$ & 196:198 & $135: 135$ & $168: 176$ & $173: 175$ & $173: 173$ \\
\hline Poiana & 129:129 & 190:198 & $135: 137$ & $170: 174$ & 169:171 & $163: 185$ \\
\hline Prima & 129:165 & 184:204 & $135: 143$ & $168: 176$ & $169: 173$ & 179:185 \\
\hline Reanda & $119: 129$ & $196: 208$ & $135: 137$ & $168: 168$ & 173:181 & $173: 185$ \\
\hline Red Rome Van Well & $123: 129$ & $186: 198$ & $135: 135$ & $168: 168$ & $173: 173$ & $163: 163$ \\
\hline Red Stayman & $127: 129$ & $196: 204$ & $127: 135$ & $168: 172$ & $169: 173$ & $163: 191$ \\
\hline Reglindis & $129: 179$ & 198:198 & $135: 135$ & $168: 168$ & $169: 173$ & $173: 173$ \\
\hline Relinda & $123: 129$ & $196: 208$ & $135: 143$ & $168: 172$ & $173: 173$ & $172: 185$ \\
\hline Remo & $119: 123$ & $178: 190$ & $135: 135$ & $168: 170$ & $173: 173$ & $163: 172$ \\
\hline Rewena & $119: 123$ & $178: 210$ & $135: 135$ & $168: 168$ & $173: 173$ & $164: 185$ \\
\hline Rubinola & 129:129 & $184: 198$ & $135: 135$ & $168: 176$ & $173: 173$ & 179:193 \\
\hline Sampion & 119:129 & 190:198 & $135: 135$ & 170:174 & $169: 173$ & 179:193 \\
\hline Sir Prize & 119:123:129 & 198:198:204 & $135: 135: 135$ & $168: 168: 168$ & 169:169:173 & $173: 179: 179$ \\
\hline Snygold & 129:129 & 198:198 & $135: 135$ & 170:174 & $173: 205$ & $173: 179$ \\
\hline$\underline{\text { Starking Delicious }}$ & $127: 129$ & 198:202 & $137: 168$ & 168:168 & 173:197 & 191:191 \\
\hline Starkrimson Delicious & $127: 129$ & 198:202 & $137: 168$ & 168:168 & 173:197 & 191:191 \\
\hline Redchief Delicious & $127: 129$ & 198:202 & $137: 168$ & 168:168 & 173:197 & 191:191 \\
\hline Redspur Delicious & $127: 129$ & 198:202 & $137: 168$ & $168: 168$ & 173:197 & 191:191 \\
\hline Topred Delicious & $127: 129$ & 198:202 & $137: 168$ & 168:168 & 173:197 & 191:191 \\
\hline Wellspur Delicious & $127: 129$ & 198:202 & $137: 168$ & 168:168 & 173:197 & 191:191 \\
\hline Topaz & 119:129 & 190:198 & $135: 135$ & 168:168 & $169: 173$ & $185: 193$ \\
\hline
\end{tabular}

${ }^{2}$ The numbers indicate the sizes of the alleles in bp. Indistinguishable sport mutations are in bold and their progenitors are underlined. In case of triploid cultivars where only two distinguishable alleles were found, the more intensive band was assumed to contain two alleles. This hypothetical third allele was indicated in italics since there is ambiguity if a null allele is involved. 
Table 4. Selection of the most efficient minimum set of SSR markers for the identification of the 46 different cultivars.

\begin{tabular}{lcc}
\hline Marker & \multicolumn{2}{c}{ Indistinguishable pairs (no.) } \\
\cline { 2 - 3 } combination & Observed & Expected \\
\hline $\mathrm{CH} 05 \mathrm{e} 03$ & 32 & 132.5 \\
$\mathrm{CH} 05 \mathrm{e} 03+\mathrm{CH} 04 \mathrm{e} 03$ & 5 & 27.3 \\
$\mathrm{CH} 05 \mathrm{e} 03+\mathrm{CH} 04 \mathrm{e} 03+\mathrm{CH} 03 \mathrm{~g} 07$ & 2 & 6.4 \\
$\mathrm{CH} 05 \mathrm{e} 03+\mathrm{CH} 04 \mathrm{e} 03+\mathrm{CH} 03 \mathrm{~g} 07+\mathrm{CH} 05 \mathrm{~d} 11$ & 0 & 1.9 \\
\hline
\end{tabular}

Comparison of the experimentally observed and theoretical efficient $\left(\mathrm{X}_{\mathrm{k}}\right)$ marker combinations according to Tessier et al. 1999. Somatic mutants were treated as one single cultivar in this analysis.

at least one allele size was common in both parent cultivars. Similarly, it looks very likely that another triploid cultivar 'Charden' derives from the fertilization of a diploid 'Golden Delicious' ovule produced by meiotic nondisjunction with a haploid pollen grain from 'Clochard Renet', as revealed by $\mathrm{CH} 05 \mathrm{c02}$, $\mathrm{CH} 05 \mathrm{~d} 11$ and $\mathrm{CH} 05 \mathrm{e} 03$ markers. This can be determined without a priori knowledge of the allelic composition of 'Clochard Renet' (pers. comm.). 'Sir Prize' is the third triploid cultivar of which one parent (also 'Golden Delicious') was present in our analysis. However, in this case, 'Golden Delicious' used for crossing was tetraploid (Williams et al. 1975) whereby the random disjunction of doubled homologue chromosomes during meiosis can produce homozygous ovules more frequently. Since the other parent ('PRI 14-152') is diploid, 'Golden Delicious' still could be determined as the ovule donor.

Successful differentiation of all apple genotypes except for somatic mutants was accomplished by using only four $(\mathrm{CH} 03 \mathrm{~g} 07$, $\mathrm{CH} 04 \mathrm{e} 03, \mathrm{CH} 05 \mathrm{~d} 11$, and $\mathrm{CH} 05 \mathrm{e} 03$ ) of the SSR markers (Table 4). Sport mutants proved to be indistinguishable from each other and their progenitors. This is not surprising since the genomes of somatic mutants differ only in one or a few small regions, which affect economically important characteristics, such as improved fruit colour, size or flavor. The chance is thus very small to find SSR marker(s) allowing us to differentiate somatic mutants.

Using the three most polymorphic SSR markers (CH05e03, $\mathrm{CH} 04 \mathrm{e} 03$, and $\mathrm{CH} 03 \mathrm{~g} 07)$ only two genotype-pairs ('Topaz'-'Goldstar' and 'Starking'-'Braeburn') were indistinguishable (Table 4). The $\mathrm{CH} 05 \mathrm{c02}$ is the fourth most polymorphic marker but still unable to differentiate the genotype pair 'Starking'-'Braeburn', which was achieved by $\mathrm{CH} 05 \mathrm{~d} 11$ marker. That is why this marker was the fourth one selected for molecular identification despite of its slightly lower PIC value (Table 1).

The probability that two different and unrelated cultivars displayed the same genotype at all investigated loci (PI) was calculated as $1.79 \times 10^{-4}$, which confirms the high potential of SSRs for differentiation of apple genotypes and that other types of molecular markers could be necessary only in case of sport mutations. Developed SSR profiles can also be used in practice, e.g., for selection of distant parents to obtain higher genetic variation in progenies, to identify outcrosses or self-pollinated individuals, which do not belong to the progeny of the applied cross, for nursery control and protection of breeders' right.

\section{Literature Cited}

Anderson, J.A., G.A. Churchill, J.E. Autrique, S.D. Tanksley, and M.E. Sorrels. 1993. Optimizing parental selection for genetic linkage maps. Genome 36:181-186.
Cabe, P.R., A. Baumgarten, K. Onan, J.L. Luby, and D.S. Bedford. 2005. Using microsatellite analysis to verify breeding records: A study of 'Honeycrisp' and other cold-hardy apple cultivars. HortScience 40:15-17.

Gianfranceschi, L., N. Seglias, R. Tarchini, M. Komjanc, and C. Gessler. 1998. Simple sequence repeats for the genetic analysis of apple. Theor. Appl. Genet. 96:1069-1076.

Goulão, L. and C.M. Oliveira. 2001. Molecular characterisation of cultivars of apple (Malus $\times$ domestica Borkh.) using microsatellite (SSR and ISSR) markers. Euphytica 122:81-89.

Guilford, P., S. Prakash, J.M. Zhu, E. Rikkerink, S. Gardiner, H. Bassett, and R. Forster. 1997. Microsatellites in Malus $\times$ domestica (apple): Abundance, polymorphism and cultivar identification. Theor. Appl. Genet. 94:249-254.

Hokanson, S.C., A.K. Szewc-McFadden, W.F. Lamboy, and J.R. McFerson. 1998. Microsatellite (SSR) markers reveal genetic identities, genetic diversity, and relationships in a Malus $\times$ domestica Borkh. core subset collection. Theor. Appl. Genet. 97:671-683.

Hokanson, S.C., W.F. Lamboy, A.K. Szewc-McFadden, and J.R. McFerson. 2001. Microsatellite (SSR) variation in a collection of Malus (apple) species and hybrids. Euphytica 118:281-294.

Kitahara, K., S. Matsumoto, T. Yamamoto, J. Soejima, T. Kimura, H. Komatsu, and K. Abe. 2005. Parent identification of eight apple cultivars by S-RNase analysis and simple sequence repeat markers. HortScience 40:314-317.

Laurens, F., C.E. Durel, and M. Lascostes. 2004. Molecular characterization of French local apple cultivars using SSRs. Acta Hort. 663:639-642.

Liebhard, R., L. Gianfranceschi, B. Koller, C.D. Ryder, R. Tarchini, E. Van De Weg, and C. Gessler. 2002. Development and characterization of 140 new microsatellites in apple (Malus $\times$ domestica Borkh.). Mol. Breed. 10:217-241.

Tessier, C., J. David, P. This, J.M. Boursiquot, and A. Charrier. 1999. Optimization of the choice of molecular markers for varietal identification in Vitis vinifera L. Theor. Appl. Genet. 98:171-177.

Williams, E.B., J. Janick, F.H.Emerson, D.F. Dayton, J.B. Mowry, L.F. Hough, and C.H. Bailey. 1975. 'Sir Prize’ Apple. HortScience 10:281-282. 